\title{
Advances in Hydrometallurgy
}

\author{
Alexandre Chagnes 1 \\ Université de Lorraine, CNRS, GeoRessources, GDR Promethee (GDR 3749), F-54000 Nancy, France; \\ alexandre.chagnes@univ-lorraine.fr; Tel.: +33-(0)372-744-544
}

Received: 2 February 2019; Accepted: 6 February 2019; Published: 11 February 2019

check for updates

The development of new technologies and the increasing demand of mineral resources from emerging countries are responsible for significant tensions in the price of non-ferrous metals. Some metals have become strategic and critical because they are used in many technological applications and their availability remains limited. In addition to energetic raw materials, such as oil or gas, the industry uses about fifty different metals. For many of them, the worldwide annual consumption ranges from a few tens of tons to several hundred thousand tons. Some of them, the so-called strategic metals, are crucial for achieving high performances. They are found in high-tech products, such as flat panel TVs (indium), solar panel cells (indium), lithium-ion batteries for electric vehicles (lithium, cobalt), magnets (rare earths, such as neodymium and dysprosium), scintillators (rare earths), and aviation and medical applications (titanium). The secured supply of these metals is crucial to continue producing and exporting these technologies, and because specific properties of these metals make them essential and difficult to substitute for a given industrial application.

Hydrometallurgical processes have the advantages of being able to process low-grade ores, to allow better control of co-products and to have a lower environmental impact providing that hydrometallurgical route is optimized and cheap. With the depletion of deposits and the growing interest in low-grade elements (e.g., rare earth elements), the metallurgical industry has shown a growing interest in the development of hydrometallurgical processes more adapted to current challenges over the last fifteen years. The need to develop more efficient, economical and environmentally-friendly processes, capable of extracting metals from increasingly complex and poorly polymetallic matrices, is real. The aim of this Special Issue was to highlight recent advances related to hydrometallurgy to face new challenges in metal production. For this goal, twelve papers have been published in this special issue in order to highlight interesting studies in the fields of precious metals, processing of primary and secondary resources and process improvement by understanding fundamental behavior and seeking alternative chemical technologies to extract, separate and produce metals or metal salts. Regarding precious metals, a special attention has been paid to evaluate the current use and future development in gold and platinum group metal recovery. More generally, four papers have been selected to introduce recent advances in the recovery of several important metals in our society: copper which is one of the most produced base metals in the world, rare-earth for obvious technological challenges and scandium because of its potential application in high-technologies as scientists and engineers have been working recently to develop new products incorporating this metal.

Although recycling will never replace primary resources, metal extraction from spent materials and tailings have not to be neglected and there are many challenges to face up in hydrometallurgy. Four papers have been selected to introduce few challenges in the recovery of rare earth elements from electronic wastes, titanium from bauxite residues and the use of ionic liquids in the recovery of metals from wastes by liquid-liquid extraction and electrodeposition.

Conflicts of Interest: The authors declare no conflict of interest. 